\title{
Path dependency when prioritising disaster and humanitarian response under high levels of conflict: a qualitative case study in South Sudan
}

\author{
Rodrigo Mena ${ }^{*}$ (i) and Dorothea Hilhorst ([)
}

\begin{abstract}
In high-conflict scenarios, humanitarian needs often surpass resources, and humanitarians are faced with ongoing challenges of whom to prioritise and where to work. This process is often referred to as 'targeting', but this article uses the concept of 'triage' to emphasise how prioritisation is a continuous and political process, rather than a one-off exercise to find the best match between needs and programme objectives. This study focused on South Sudan, exploring the formal and informal dynamics at the national, regional and local levels of humanitarian decisions. The article is based on semi-structured interviews and multiple meetings and observations of programmes over four months of fieldwork in 2017. This fieldwork was beset by many of the problems that humanitarians also encounter in their work, including complicated access, logistics difficulties and security challenges. Humanitarian action is meant to be flexibly deployed to respond to priority needs resulting from conflict or disasters, and agencies have multiple tools and policies to facilitate this. However, in reality, we find humanitarian action largely locked into path-dependent areas of intervention because agencies must rely on logistics, trust and local partners, all of which take years to develop, and because local actors' commitment to see programmes continued.
\end{abstract}

Keywords: Humanitarian aid, High-intensity conflict, Targeting, Triage, Politics of prioritisation, Disaster response, Path-dependency, South Sudan

\section{Introduction}

Humanitarian action is supposed to be agile and fast in responding to disasters. For present-day disasters, it usually takes only $24 \mathrm{~h}$ before basic needs surveillance is completed and aid is on the way. The international community has become highly organised in coordinating disaster response, through the virtual On-Site Operations Coordination Centre, ${ }^{1}$ for example, enabling the quick matching of needs and capacities, with all authorities,

\footnotetext{
1 The On-Site Operations Coordination Centre is a 'tool that provides a platform for the coordination of international response activities in the immediate aftermath of a sudden-onset emergency or a rapid change in a complex emergency' (OCHA 2018:3).
}

\section{*Correspondence: mena@iss.nl}

International Institute of Social Studies (ISS) of Erasmus University

Rotterdam, Kortenaerkade 12, 2518 AX The Hague, The Netherlands international agencies and donors able to follow what is required in real-time. The question is whether this applies equally to disasters that happen in conflict areas. In such contexts, the response to a disaster is likely hampered by the multiplicity of challenges characterising humanitarian activity in conflict areas. However, conflict areas have the advantage of humanitarian agencies already being present and operational; these agencies can thus be expected to be agile in refocusing their activities to respond to the disaster.

The case of South Sudan in general and particularly the response to the famine declared by the United Nations (UN) (2017) in 2017 presents a sobering picture regarding the agility of humanitarian action. Although the World Food Programme and some other aid actors managed to reach the affected areas soon after the

\section{Springer Open}

(c) The Author(s) 2022. Open Access This article is licensed under a Creative Commons Attribution 4.0 International License, which permits use, sharing, adaptation, distribution and reproduction in any medium or format, as long as you give appropriate credit to the original author(s) and the source, provide a link to the Creative Commons licence, and indicate if changes were made. The images or other third party material in this article are included in the article's Creative Commons licence, unless indicated otherwise in a credit line to the material. If material is not included in the article's Creative Commons licence and your intended use is not permitted by statutory regulation or exceeds the permitted use, you will need to obtain permission directly from the copyright holder. To view a copy of this licence, visit http://creativecommons.org/licenses/by/4.0/. 
declaration, this was either impossible for the vast majority of non-governmental organisations (NGOs), or it took some of these organisations a rather long time to access famine-affected areas, despite the availability of significant funds and the sense of urgency brought by the declaration of famine. This study explored the response to disasters in conflict settings using the case of the 2017 drought in South Sudan.

Understanding the particulars of disaster response in conflict-affected areas is of paramount importance. Caso (2019) reported that, from 1960 to 2018, the average yearly percentage of countries affected by conflict while also facing a disaster was $67 \%$. From 2009 to 2018 , the average yearly co-occurrence of conflicts and disasters was $78 \%$, meaning that the population of almost four out of every five countries affected by conflict in a given year also had to cope with at least one major disaster in the same year. Most deaths caused by disasters occur in conflict-affected and fragile states (Peters 2017), and the impact of a disaster on people's livelihoods is greater in conflict-affected and fragile contexts (Hilhorst 2013; Wisner 2012).

While the exact nature of the relation between disaster and conflict is still subject to debate, the co-occurrence of disaster and conflict is evident when we unpack the elements that make up disaster risk. Since the 1980s, there has been a broad consensus that disasters related to hazards such as droughts, floods, storms, or earthquakes are far from natural. As expressed by the pseudo-formula of $\mathrm{DR}=\mathrm{H} *[(\mathrm{~V} / \mathrm{C})-\mathrm{M}]$, disaster risks $(\mathrm{DR})$ come about when hazards $(\mathrm{H})$ meet vulnerability $(\mathrm{V})$, and can be counteracted by multiple variables, including capacities (C) and mitigation (M) (Wisner et al. 2012, p. 24). Disaster risk reduction encompasses all 'systematic efforts to analyse and reduce the causal factors of disasters. Reducing exposure to hazards, lessening the vulnerability of people and property, wise management of land and the environment, and improving preparedness and early warning for adverse events' (UNISDR 2017: online). The main interrelated variables in the process of reducing the risk of disasters are the mitigation of hazards, individual and social preparedness (Benson et al. 2007; Buckle 2012), capacity development (Ginige et al. 2010; Rose and Jayawickrama 2016; UNDP 2010; Wisner et al. 2012) and building, improving and maintaining people's resilience (Davoudi 2012; Kelman 2008; Manyena et al. 2011; Paton et al. 2000).

Conflict may contribute to disaster risks through adversely affecting any or all of these elements. First, hazards such as floods or droughts come about through natural-social interaction, and they can be magnified because of, for example, unsustainable land use, water management or deforestation. Second, conflict may intensify vulnerability or push people to be exposed to disasters. Areas in conflict usually rank among the lowest on all indicators related to the Sustainable Development Goals, with a high prevalence of poverty, disrupted markets and a lack of access to health care (Mena 2018). Conflict also creates displacement, leaving people in places with greater exposure to hazards. Finally, weak governance, a lack of political will, damaged infrastructure and the de-prioritisation of disasters in the face of other problems negatively affect the capacities to respond to a disaster and the general disaster governance process.

Disaster governance, as an overarching concept, includes the policies and normative frameworks through which multiple actors work on disaster risk reduction, including disaster management, disaster response and disaster knowledge production. Disaster governance comprises actions at international, national, regional and local levels and includes social, economic and political dimensions. Disaster governance includes every actor involved in disaster-related action, including members of the government, civil society and individual citizens, humanitarian and development systems and private actors (Field and Kelman 2018; Hilhorst et al. 2019a, 2019b; Tierney 2012; UNISDR 2017). Figure 1 depicts the complex relationships between conflict and the multiple elements of the governance of disasters, including the production and reduction of disaster risk.

Although disaster studies have increasingly paid attention to the relationship between disaster and conflict, previous studies have rarely distinguished between different types of conflict. However, humanitarian actors acknowledge that practices and challenges heavily depend on the type of conflict scenario (van Voorst and Hilhorst 2017). A thorough analysis of disaster response, then, requires considering the conflict scenario in which the response occurs (Ahrens and Rudolph 2006; Field and Kelman 2018; Hilhorst et al. 2019a, 2019b). The study presented here is part of a larger research programme that distinguishes high-intensity, low-intensity and postconflict scenarios.

We know little about the everyday practices of disaster response in high-conflict situations. A remarkable exception is a study conducted by Maxwell and Majid (2015) that provides a detailed account of the 2011 drought response in Somalia. This drought was the worst to hit the Horn of Africa in 60 years. In Ethiopia and Kenya, state, non-state and international actors managed to respond in time to prevent the mass casualties that would have resulted from a lack of water and food security. In Somalia, however, the drought resulted in an estimated 260,000 deaths (Maxwell and Majid 2015). This was partly because of the long-term conflict that had rendered Somalians extremely vulnerable to drought and 


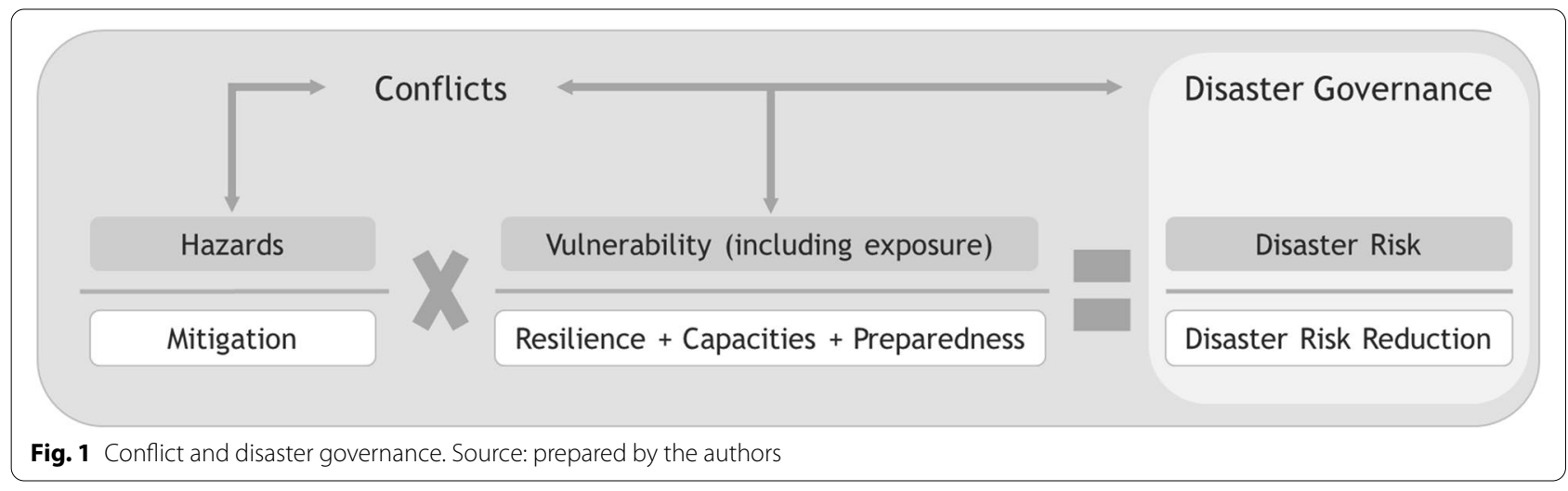

the ongoing operations of al-Shabaab, which restricted people's ability to migrate to safer areas. The death toll was also exacerbated by the counterterrorist measures of donors, especially the USA. An important outcome of the case of Somalia was the development of the Integrated Food Security Phase Classification (IPC scale) as a 'tool for food security analysis and decision-support' (USAID and FEWS 2011). Among other reasons, this was promoted to have a standardised tool to inform decisionmaking processes while avoiding the political pitfalls of targeting. The case of Somalia also shows the need to invest more in research into these types of scenarios to identify lessons that can contribute to making disaster response in conflict conditions more effective. Therefore, this study focuses on disaster response in high-conflict scenarios, using the case of the 2017 drought in South Sudan, which happened at a time when the country had relapsed into conflict for several years.

In high-intensity conflict (HIC) scenarios, disaster response needs are usually much greater than the available resources and capacities. An important question driving our study was how aid actors working in such contexts decide where, for whom and how to employ their (limited) resources. According to the humanitarian principles, resources should go where the need is greatest. We would thus expect international NGOs (INGOs) operating in countries with HIC to redirect their resources to disaster-affected areas when needs suddenly arise. This study aimed to reconstruct how decision-making about the allocation of aid takes place in South Sudan, examining decision-making processes at the national level, at the decentralised level and finally at the level of programme implementation.

In the jargon of humanitarian aid, the allocation of resources is done based on targeting and needs assessments 'to quantify immediate needs for emergency assistance, so that response programmes can be quickly designed' (Maxwell and Watkins 2003:78). Here, we evoke an older term-triage-to study these processes. Triage describes how medical doctors decide which patients are most urgently in need of assistance. Triage is similar to targeting on the basis of needs assessment, but we prefer to use this term to step away from the technocratic notion of targeting, to analyse the (political) processes through which decisions are being made and continuously renegotiated, and to remain mindful about the painful decisions implied in triage. After all, in many cases, the choice is not about finding those who are the neediest, but rather about choosing between communities that are equally in need. As presented by Orbinski and Reed (2009):

Triage is the ultimate humanitarian nightmare. Racing against time with limited resources, relief workers make split-second decisions: who gets treatment; who gets food; who lives; who dies. This impossible dilemma understandably haunts humanitarians [...]

This article is based on qualitative interviews that focused on the challenges of disaster response in an HIC setting, multi-actor collaboration processes (between local, national and international aid and society ${ }^{2}$ actors) and the processes that determine where aid flows. We also asked the research participants for their recommendations for improving disaster response in highconflict scenarios. After the presentation of the case of South Sudan, the following sections explore the nature of HIC scenarios, describe our approach to humanitarian aid and analyse what is understood by the targeting and triage of aid. The methodology used in this study and the main findings are then presented, followed by

\footnotetext{
${ }^{2}$ Aid actors refers to all individuals and organisations that see humanitarian actions as the core of their actions. Society actors can participate in humanitarian actions, but these actions are not their main role, for example, disaster or conflict affected people.
} 
recommendations. In the final section, we discuss the results and conclusions.

\section{High-intensity conflict and the case of South Sudan}

An HIC scenario is an analytical category proposed to represent moments in a protracted crisis where widespread violent conflict occurs, leaving over 1000 casualties per year. In such scenarios, state fragility is usually high, and the capacity of the local and national authorities to maintain control over vast regions of the territory is minimal or non-effective. As a result, 'the provision of goods and basic services is irregular or fragmented, causing, together with the levels of violence, high rates of migration of people looking for safety from their localities, regions, or countries', resulting in a complicated situation for the provision of humanitarian assistance (Mena 2018, p. 31). HIC scenarios present a particular set of challenges for humanitarian aid and disaster response. The most obvious include issues of security and the difficulty of reaching people in need (Duffield 1994; Wisner 2012; Young and Maxwell 2009). Additionally, HIC scenarios are also characterised by complex governance arrangements at the local or national level, the presence of parties contesting the state, economic crisis or disruption, and a deficiency of information or reduced access to data (Mena 2018). High levels of bureaucracy, complex and changing logistics and corruption are also commonly present in HIC scenarios. As a result of these challenges, 'UN agencies and INGOs are increasingly absent from field locations, especially when there is any kind of significant security or logistical issues' (Médecins Sans Frontières in Healy and Tiller 2014, p. 4).

Following a two-level case-selection strategy (George and Bennett 2005; Gerring 2007), South Sudan was chosen as a typical case of an HIC scenario that also has a high prevalence of disasters. The long-term social conflict affecting the country, as well as the floods and droughts impacting regions of South Sudan, informed the selection process. South Sudan's independence from Sudan in 2011 came after more than 40 years of conflict between the South and the North of what was until that time Sudan. Two years after independence, conflicts between factions of the new government and a severe economic crisis led to an internal crisis and civil war. Consequently, the country experienced a severe humanitarian crisis that has resulted in more than two million internally displaced people and another two million people leaving the country as refugees (UNHCR 2017). A cholera outbreak with hundreds of casualties, over a million cases of malaria and severe malnutrition added to the crisis (WHO 2017). Finally, as mentioned above, in February 2017, famine was declared in some areas of the country (United
Nations 2017). Disasters are also present in the country. South Sudan regularly faces multi-year droughts, large areas of the country are seasonally flooded (Government of the Republic of South Sudan 2015; Marriage 2006) and the country also experiences earthquakes.

It is not easy for humanitarians to respond in South Sudan (Tanner and Moro 2016). The level of infrastructure is low, roads are in poor condition, vast areas of the country are flooded for several months each year and the situation is, in general, not safe. In 2017, the country was repeatedly depicted as one of the most dangerous places in the world for aid workers (see Cole 2017; Gaffey 2017; Little 2017). Since the current conflict broke out in 2013, almost 90 humanitarian workers have been killed in the country, and 82 humanitarian access incidents were reported in the first half of 2017, including attacks, threats, intimidation and harassment (OCHA 2017b).

\section{Targeting and the triage of aid}

Targeting refers to the process of deciding which populations and places need assistance, which type of assistance is needed and when and how this assistance will be delivered, including mechanisms aiming to ensure that aid is provided only to people who meet certain criteria (Maxwell et al. 2011; WFP 2006). Targeting aims to balance quality and quantity, when efficiency in humanitarian action makes it possible to save more people, but possibly at the risk of compromising quality (Hopgood 2008). The process of targeting can be divided into two main moments: (1) identifying people in need and (2) selecting the delivery and distribution mechanism (WFP 2006).

The most relevant aspect of targeting is the question of who requires assistance (Young and Maxwell 2009:8). This question also entails deciding which people will be selected not to receive aid, at least for the moment. There are also always other factors playing a role in targeting, such as the humanitarian principles and questions of access and security. This makes targeting not only about the question of 'who', but also about 'when', 'where' and 'how' to provide assistance (Maxwell et al. 2011; Patel et al. 2017; Young and Maxwell 2009).

Targeting happens at different levels of decision-making. The first level concerns administrative targeting, which is done by (humanitarian) policymakers based on needs assessment reports and other necessary data. The second level is community-based, where service providers, usually in consultation with community leaders, identify lists of people or households eligible for assistance. Third, self-targeting happens at the individual level, where those entitled to assistance decide whether to participate in the aid scheme (Maxwell et al. 2011; Patel et al. 2017). 
Triage was originally a medical concept, used to describe the process of prioritising which patients would be treated first and how, on the basis of the degree of urgency of the patients and their anticipated results. When there are limited resources and capabilities to treat and provide aid to those affected, it is necessary to sort these people and prioritise care. Similarly, in places affected by high levels of conflict, the number of people in need of assistance is usually so large that the resources and capabilities available do not allow providing aid to them all, resulting in the need to prioritise between the affected people and to target aid towards those assigned the highest priority (Orbinski 2009).

In medicine, the triage process usually involves a twostep analysis: (1) assessing the number of people in need and their specific needs ${ }^{3}$ and (2) evaluating the capacities in place to respond. Although this is similar to targeting, the idea of triage has invited more reflection on the ethical difficulties involved. Adopting the concept of triage also facilitates the exploration of questions beyond the narrow targeting notions of 'who' and 'where' (Young and Maxwell 2009). Targeting conveys a sense of rationality and precision that seems to gloss over the complexities involved and appears to divert attention away from affected people who fall outside the targeting decisions. Triage has previously been used to describe the difficulties that humanitarian aid workers and responders face when they have to choose between crisis and disasteraffected populations (e.g. in Dr Orbinski's [2009] $A n$ Imperfect Offering and the documentary Triage: Dr. James Orbinski's Humanitarian Dilemma (see Orbinski and Reed 2009)). Redfield (2008) also used the term triage to describe and explore the difficulties of prioritisation. In this article, we use triage to highlight the dilemmas involved and to enable a focus on the everyday politics of deciding who will receive assistance and who will not.

\section{The humanitarian arena: aid and society actors}

In this article, we focus on the everyday politics and practices (Hilhorst 2018, p. 30) of triage, starting from the idea that the outcomes of humanitarian decisionmaking are based on more than objective and neutral parameters (Barnett and Weiss 2008; Wood et al. 2001).

\footnotetext{
${ }^{3}$ In this analysis, patients are usually separated into three to five groups and tagged with a number or colour-coded label: Patients assigned to the first group are those who, although they are affected, are in a condition that allows them to wait for help, as their injuries are not life-threatening (white label or Number I). Patients in the second group are those who will not survive without immediate assistance and for whom the capabilities in place are sufficient to aid them and reduce their risk of death (red label or Number II). The final group comprises deceased people and those who, with the capacities available, will not survive regardless of any treatment (black label group or Number III). As stated in a quote before by Orbinski and Reed (2009), applying the same principle to prioritise humanitarian aid is a process of deciding 'who gets treatment; who gets food; who lives; who dies'.
}

Adopting an actor-oriented approach, this research sees humanitarian aid and disaster response as an arena, seeking to represent 'the outcome of the messy interaction of social actors struggling, negotiating and trying to further their interests (Bakewell 2000, pp. 108-9 in Hilhorst and Jansen 2010, p. 1120). The relevant actors include humanitarians, authorities, communities and usually many others such as civil society, the media, the military, armed groups and religious institutions (De Waal 1997; Wood et al. 2001).

Policies matter in our approach, but they are seen as translated through 'people's practices, including all social-political strategies and negotiations, formal and informal actions and everyday practices occurring in, and for the delivery of, aid' (Mena 2018, p. 38; see also Hilhorst and Jansen 2013). Interactions and negotiations make up the everyday politics of aid that ultimately determine the control, allocation, production and use of resources and the values and ideas that surround aid delivery (Kerkvliet 2009). Everyday politics are as much a part of formal policy processes among authorities and powerful organisations as of the practices of service delivery, therefore, 'the everyday politics of conflict and disaster and crisis response' always plays a role in this sphere as well (Hilhorst 2013, p. 1).

\section{Methodology}

This qualitative case study comprised of desk review and fieldwork phases. After 6 months of desk review, ${ }^{4}$ fieldwork was carried out in western, central and eastern Equatorial; western and northern Bahr el Ghazal; Unity; Lakes; and Jonglei regions of South Sudan during February and June 2017 by the first author. Additional fieldwork was conducted in Uganda at the border with South Sudan and in multiple refugee settlements (Imvepi, Rhino Camp, Bidi Bidi and Adjumani) and reception centres. These interviews included people that fled South Sudan and aid actors that have been working on both side of the borders. Some research participants indicated that by being in Uganda, they can speak more freely about their experiences in South Sudan, which helps to have longer or more open conversations. ${ }^{5}$

The data collection comprised a total of 43 semi-structured interviews, observation of over 20 coordination

\footnotetext{
${ }^{4}$ The desk review material consisted of books, journal articles, reports, and policy documents and protocols on the topics addressed, focusing on those published in the last two decades. The review also included grey literature and audio-visual material, such as blog entries, websites and documentaries.

${ }^{5}$ In the case of people affected by disaster and conflict, talking with them in Uganda also entailed some challenges. In their words, they recognised to start our conversations saying what they thought will help them to receive humanitarian aid or refugee status. Only after having long-term interviews was it possible to establish a connection with the people, in which they understood we were not humanitarian workers.
} 
Table 1 Interview and focus group participants

\begin{tabular}{|c|c|c|}
\hline Type of actor & $\begin{array}{l}\text { Number of } \\
\text { interviews }\end{array}$ & Brief description of participants \\
\hline United Nations (UN) agency representatives & 8 & International and national programme managers and coordinators \\
\hline International non-governmental organisation representatives & 12 & $\begin{array}{l}\text { Country directors, programme and project managers and staff } \\
\text { members }\end{array}$ \\
\hline Local and national non-governmental organisation representatives & 3 & $\begin{array}{l}\text { Managers and staff, mostly South Sudanese, but also international } \\
\text { actors from neighbouring countries }\end{array}$ \\
\hline National-level government officials & 3 & All South Sudanese men \\
\hline Local government officials and other local authorities & 3 & \\
\hline Donors & 3 & $\begin{array}{l}\text { All men, one representing one governmental donor, one UN donor } \\
\text { and one inter-state organisation }\end{array}$ \\
\hline Academics/researchers & 6 & From South Sudan, Uganda, Kenya and the Netherlands \\
\hline Contesting party officials & 2 & Both South Sudanese men \\
\hline Private sector actors & 3 & From the transportation, financial and building supplies sectors \\
\hline
\end{tabular}

meetings of multiple aid actors, 13 visits to areas affected by disasters and conflict. Thirteen focus groups (2-10 people per group) were also organised with men and women from affected communities, protection of civilians' sites, refugee settlements, reception centres and urban areas of the country. Detailed research and fieldwork protocols were developed to facilitate the conduct of ethical and safe fieldwork research.

Recognising that experiences and views of humanitarians depends on their positionality, a broad variety of research participants was interviewed (see Table 1), including international and local staff members of UN agencies, INGOs and NGOs; governmental actors at national level; local government and other local authorities; people affected; donors; academics and researchers; contesting party officials and private sector actors, including representatives from local institutions and organisations.

For the data analysis, a thematic content analysis was performed, and the explanation-building technique was applied. The content analysis was informed by themes developed while reviewing the literature, and emergent themes were added as necessary during the analysis of the study data. The six main themes orienting the analysis were (1) challenges of providing aid and disaster response; (2) coordination and decision mechanisms; (3) everyday politics related to triage; (4) the official politics of triage; (5) negotiation strategies and processes; and (6) solutions and best practices. All anonymised interviews, field notes and observation field reports were transcribed, coded and organised using NVivo 11.

Reaching participants was challenging for multiple reasons. First, there was a lack of reliable communication (mobile signals and Internet access are almost nonexistent in some areas of the country, and there are no landlines). Second, staff turnover was high. Third, many relevant actors were deployed in remote places all over the nation. Another important challenge involved the issue of trust. Because of the conflict in the country, many actors involved in aid were cautious when speaking with outsiders. Finally, the historical and current conflict of the country have led to a lack of information, including demographic data. Other challenges related to a lack of proper infrastructure, bad roads and the limited availability of petrol. Security and safety constraints impeded travel to many areas.

It should also be noted that a significant number of interviews were not recorded, as per the request of the interviewee. In some cases, interviewees even requested that no handwritten notes be taken. Likewise, in the participatory observation conducted during the fieldwork visits, recording, taking pictures, filming and even notetaking were restricted. The researcher carrying out the fieldwork (the first author) had prior experience applying techniques to memorise collected information, and notes were written down as soon as possible. Whenever possible, the main parts of the reconstructed interviews were later validated with the participants.

\section{Findings}

This section presents the main findings, starting with the challenges and constraints of HIC scenarios, the need to prioritise in the provision of aid and disaster response and the process and negotiation involved in the different levels of decision making in HIC scenarios.

\section{Challenges and constraints of HIC scenarios}

For most aid actors, the main challenges of humanitarian aid provision (including disaster response) in HIC scenarios are complex logistics (especially related to 
access) and obtaining funds. Poor infrastructure; the lack of roads, electricity and potable water; and reduced access to some regions of the country during the rainy season result in additional problems for those providing humanitarian aid. To overcome these difficulties, aid actors need to rely on a complex and expensive set of resources, such as aeroplanes, helicopters, generators and fuel and build essential infrastructure from scratch. This challenge is particularly affecting national and local NGOs, that need to find resources to maintain their infrastructure (office, vehicles, computers) at high cost, while humanitarian projects rarely cater for overhead (Tanner and Moro 2016).

Participants noted that South Sudan is among the most expensive places to operate, and, even with funds secured, problems such as the country's hyperinflation can make planned budgets insufficient. Reduced access to funds was described as the primary challenge to operating by local and national NGO and governmental representatives. Donors, INGO representatives and UN officials also noted that South Sudan is expensive, even compared with other HIC crisis contexts, but they did not find this challenge more significant than other challenges.

Insecurity is another important challenge. All interviewees described South Sudan as unsafe, making it difficult to access affected places and places where aid is distributed. While aid actors are more exposed to illegal checkpoints and the risks of robberies, ambushes, landmines, bombs, shootings and kidnappings, society actors also face the risks of rape, abduction of minors to join armed groups and death in clashes or as retaliation. Additionally, insecurity leads to displacement, which makes it difficult to know the number and profile of affected people, as well as presenting an obstacle to reaching them.

Access and insecurity also relates to the competition among armed groups for humanitarian assistance and the benefits of aid. The control over some territories is often related to the use of humanitarian aid for non-humanitarian purposes, usually related to conflict dynamics (Deng 2018).

\section{The need to prioritise}

The enormous need for humanitarian assistance combined with the limited response capacities because of major challenges to aid provision make South Sudan an ideal case in which to study processes of triage. The UN Office for the Coordination of Humanitarian Affairs' (OCHA) Humanitarian Response Plan for South Sudan (HRP) aims to 'implement a strictly prioritised, targeted and coordinated response' (OCHA 2016, p. 18). The HRP recognises that the prioritisation of aid is necessitated by a lack of response capacity, given the extent of the crisis:
In the face of rapidly growing needs, the plan represents the result of robust prioritization and difficult decision-making by humanitarian partners [...] The plan acknowledges that, given the expansion and deepening of the crisis, humanitarians will be able to meet only the most urgent and severe needs [...] As South Sudan is a uniquely challenging and costly operational environment, the plan endeavours to maximize efficiency. (OCHA 2016, p. 17)

Prioritisation was a major issue for the aid actors participating in this research. Despite the many obstacles, they usually felt confident about their ability to carry out their programmes. One INGO manager stated, 'We have been doing this for ages', referring to the five decades of accumulated experience with working in the complex scenario and actual territory of South Sudan. Other aid actors mentioned that negotiating access with armed groups, airdropping food, overcoming dangerous scenarios, and reaching remote communities have become common practice in the humanitarian aid sector, and they have been improving and implementing these practices for decades. However, the scope of programming is not infinitely elastic, and, as one UN official expressed, 'We know how to respond, but we cannot do it for everyone and everywhere.6

In South Sudan, as in most internationally driven responses, the first level in terms of the politics and mechanism of this prioritisation comes from the Humanitarian Needs Overview (HNO) and the HRP. The HNO, developed by OCHA, works as an umbrella document covering the full scale and scope of needs in any given context' (IASC 2015, p. 3). Within this needs framework, the HRP is developed by setting the boundaries and scope of the response. For example, the food security and livelihoods (FSL) cluster established the following as its target and priority:

Systematic prioritization will remain the cornerstone of the FSL response. FSL partners will target some 4.5 million people out of some 4.9 million in need of assistance. FSL partners will prioritise critical 'IPC [Integrated Food Security Phase Classification] phase 3, 4, and 5' caseloads. Life-saving assistance will be prioritized. The FSL Cluster will also advocate for resources for interventions that help prevent a further expansion and deepening of food insecurity in the coming years. (OCHA 2016, p. 19)

Although targeting and prioritisation are commonly explained in terms of funding and budgeting, in interviews and conversations during the fieldwork, it was

\footnotetext{
6 This phrase was mentioned in a non-recorded interview and thus may not represent the exact words used by the interviewee.
} 
common to hear that, even if there were enough funds to assist everyone in the country, aid actors would still need to prioritise. Triage is a process that involves ethical questions and weighs variables such as the safety of humanitarian actors, the real need to respond and the expected impact of programmes on affected communities.

As mentioned above, triage entails a two-step analysis, assessing people in need and evaluating the capacities in place to respond. The interviewees emphasised that the issue of capacities is first and foremost translated as the capacities of the affected communities. A major recurring consideration was whether communities could survive, be resilient, and adapt or respond to the events without external help, either from local or national governments or from INGOs or UN agencies. Two participants (from an UN agency and an INGO) mentioned that, when communities were found to be capable of responding and coping on their own, their organisations would use their limited resources in other communities-those that were unable to thrive without external help. Another important variable concerned aid efficiency. As expressed by one INGO staff member, 'Sometimes we have to choose between going to multiple communities where we can do something or going to the one most urgent area where we probably don't make much difference anyway'.

\section{Different levels of decision making}

The spaces and moments for triage vary from formal coordination meetings to informal social gatherings, as will be elaborated below. The main aspects negotiated are funds, places, resources and moments. This happens at three main levels in the country: national, institutional and local. At the national level (Level 1), triage occurs in meetings of aid clusters, donors and the Humanitarian Country Team. The institutional level (Level 2) concerns official institutional politics. It refers to the internal discussion and coordination occurring inside each aid organisation and each government ministry or department coordinating action at the national or regional level. The institutional level may be seen as the hinge between macro policies and actual implementation. This level usually encompasses NGOs' national offices, ministries, individual UN agencies and the private sector. The local level (Level 3) concerns the field offices (I)NGOs (including local and national ones, although local ones might only participate in Level 2 and 3), UN agencies, governmental officials, local branches of private companies or organisations including churches and civic organisations and often the recipients of aid.

In meetings at and between these levels, the most recurrent question when performing triage was whether it was feasible to respond, considering the insecurity in the country, access constraints and the lack of infrastructure and services. In two meetings, one between regional authorities and aid representatives and another between $\mathrm{UN}$ agencies and NGOs, decisions to decline to respond to a community need were based exclusively on the feasibility question. In both meetings, the decision was not presented as final. It was agreed to monitor the situation closely and seek alternatives if necessary. A participant in one of these meetings later told the first author that 'Making the decision not to help everyone is painful' (INGO manager). Like Redfield, she considered the triage of aid to be painful because it 'reminds humanitarians that they themselves participate in the selection' (Redfield 2008, p. 209). Leaving decisions partly open for future developments may be seen as one way of coping with this painful process.

Although feasibility has many aspects, it is often related to funding. For many research participants, including government officials, NGO and private sector representatives, and contesting party officials, the lack of funds was one of the primary factors hindering humanitarian aid and forcing them to triage among the multiple affected groups and places. During the interviews, exorbitant costs and a lack of funds were often mentioned as a tipping point in the decision not to respond. $\mathrm{UN}$ actors and donors, in contrast, maintained that there are enough resources to respond in South Sudan, locating the problem instead in the lack of human resources, capabilities on the ground and the unsustainability of carrying out projects because of the conflict.

Local capacities and community resilience were another aspect playing a prominent role in meetings, social events and interviews. Decisions not to provide assistance for a certain community were often couched in the argument that the community could manage without help. HIC scenarios are part of protracted crises, and affected populations develop multiple coping and survival mechanisms. The problematic part of this in South Sudan, however, is that the conflict has damaged many of those coping mechanisms, and the analysis of communities must therefore be a constant process. Although the research participants often realised that the resilience/capacity argument may be unjustified and mask a more complex and changing situation in terms of need, the routine use of this argument may be seen as another means for aid workers to alleviate the 'pain of triage'. By banking on community capacities, aid workers can avoid the sense that they are abandoning communities.

The divisions between the three levels of decisionmaking described here are often blurred, but each level is nevertheless characterised by specific styles of decisionmaking, foregrounding particular values in the narratives 
of aid workers. The following sub-sections detail how aid is negotiated at each of these three levels of official and everyday politics.

\section{Level 1: national-level triage}

The first level of the official politics of triage in the studied HIC setting has a national focus, occurring in cluster, donor and Humanitarian Country Team meetings, that are consisting of expatriate humanitarians and national authorities. At this level, negotiations seem to focus on universality, consensus, and transparency. Every participant working at this level mentioned that the main aim is to decide whom to assist based on objective information and through a transparent and well-informed process. The ultimate official aim is to help everyone who needs assistance, without discrimination. Decisions, in the narrative of this level, are primarily evidence-based.

At this level, triage is negotiated and discussed between known and established parties. Organisational representatives know each other well and understand the rules and procedures of participation in the meetings. The number of actors involved in these meetings is usually low (around five to eight participants). Meeting participants are aware that their decisions must be seen as transparent as possible, and this is a major incentive for aiming to reach decisions by consensus or at least explicit acceptance by the parties involved and to uphold the practice of framing decisions according to clear objectives and parameters. There must be regulatory frameworks (national or international), and the final result is formal and public. Officially, they seek to aid everyone in need of assistance. The final decision pertains to resource flows designated to agencies, plans and programmes.

In the shadow of these formal, consensus-driven and evidence-based processes, multiple, and not always openly recognised, actors are involved in the negotiations. For example, groups contesting the state may come into the picture because they are needed to secure safe access for UN agencies and NGOs, and these groups may insist on providing aid to certain groups in exchange for this. Agreements made during these shadow negotiations are kept off the record and do not appear in official documents. As one official of an international organisation said,

Everyone knows [that they negotiate with parties contesting the state]. In some meetings, we can talk about this, but of course we cannot say this on record, especially when there are government officials, because we have [to appear] to be neutral.

Another example of everyday political action at the national level is some organisations' non-attendance at coordination meetings, as observed and mentioned by multiple informants in South Sudan. Non-attendance at meetings can happen when an actor does not agree with the actions to be proposed by the government or other aid actors, but to maintain good relationships, they do not want to say 'no' to them. By not going to the meeting, they avoid being part of the process, or they may be able to boycott some actions that require that a certain number of actors be involved in the decision

For example, there was a project that could not be carried out because an INGO did not attend both meetings where a 'memorandum of understanding' was to be signed with the government that was needed to implement some projects. In both occasions, the INGO justified their non-participation for security reasons. In subsequent conversations, some NGOs present at that meeting explained that the project included an early pregnancy prevention component. The INGO that did not attend the meeting is a faith-based organisation which is not in favour of pregnancy prevention actions. Other actors choose non-attendance because they have not achieved or done what was agreed, or they do not have the information or capacity to adequately participate in the agenda of the meeting; they therefore do not attend to avoid being seen as lacking in competence. These are examples of everyday resistance in which an organisation unofficially claims or rejects certain actions.

Similar results associated to everyday resistance were found by Marriage (2006, p. 480) studying 'the disconnect between the universality professed by aid organizations and the reality of their operations, and the ways in which they deal with this disconnect'. Marriage found that aid actor use strategies as fantasy (of possible positive outcomes of their actions not always aligning with the real outcomes possible in those contexts) and denial. While fantasy provides comfort, denial allows to deal with what is known and relegating to the not-known what is better avoided acknowledging, for example, the impossibilities to aid everyone in places under HIC. Denial and fantasy are, as found by Marriage, key for aid actors (including donors) to be able to sustain their responses.

\section{Level 2: institutional triage}

The second level concerns decision-making inside an aid agency, government ministry or department. The negotiations are generally internal to the organisation or between the organisation and its (implementing) partners. At this level, efficiency and accountability are key concepts in the narrative of the official politics. Decisions are based on an in-depth analysis of their own capacities, which is set against the objective to help the neediest or go where the situation is the most urgent.

Decisions aim to aid a population that is usually broadly defined in the first level of decision-making in a way that 
enables the highest efficiency and accountability possible in the situation. Hence, it is recognised that there is insufficient capacity to assist everyone; therefore, it is necessary to triage-to prioritise beyond and between the populations fitting the initial target criteria. Maximising efficiency and accountability is often achieved by partnering or coordinating with other organisations.

Beneath the decision-making processes, the interviews revealed everyday politics that are oriented towards creating and maintaining networks among aid agencies. It is well-known and it was regularly mentioned in the interviews that casual gatherings are the settings where aid actors get together and strengthen their relationships. We found that many problems, agreements and collaboration practices are discussed at these informal gatherings. It often happens that decisions are pre-discussed in an informal setting and later formalised through the practices of official politics in each organisation or via partnership agreements. Rather than making decisions about when, how and whom to assist based on a set of criteria, such decisions thus came about through experience-based informal interactions. Maintaining favourable and trustworthy relations can thus be seen to underpin official decision-making. This provides an example of the everyday politics of support and compliance (Kerkvliet 2009).

\section{Level 3: local triage}

At the local level, decisions with regard to humanitarian aid and disaster response are rooted in a narrative centring on the concepts of feasibility and efficacy. In South Sudan, at this level, the aim is to help those who need assistance and 'that we can help'. This sentiment was commonly expressed during the interviews and field visits. Unlike the process at the first level, at this level, it appears legitimate to negotiate with local society actors, including parties contesting the state and affected communities, alongside consultations with other aid actors on the ground. As decisions need to be informed by local knowledge, local actors may find an advantage in negotiating room to initiate or continue activities, informed by their vested relationships and loyalties.

Decision-making at this level involves a multitude of actors that may have very divergent styles of operating. In some places in South Sudan, the process included nine types of actors: field offices of international and local NGOs, UN agencies, governmental officials, private companies, churches, civic organisations, representatives from associations of aid recipients residing in nearby protection of civilians' sites and security forces. Other areas saw less complexity, with decisions made only between INGO staff members, one UN representative and community leaders. In line with results presented by Young and Maxwell (2009) about targeting in a complex emergency, the participation of the communities of affected people in South Sudan was limited in decisionmaking processes.

The official politics of triage concerns who can effectively be assisted while safeguarding the security and resources of all actors involved. At this level, there is less of an (artificial) separation between official and everyday politics. All involved actors accept that working at the level of implementation is often messy and requires a great deal of creativity and flexibility. Negotiations are focused on maintaining the legitimacy of the actors providing aid or disaster response. As mentioned by all NGO representatives and four INGO staff members, aid actors can only decide to operate in places where they know they are accepted; otherwise, their actions could be seen as coercive and violent, resulting in insecurity and volatility.

Participants noted that acceptance is crucial to their capacity to implement programmes. Acceptance and legitimacy must be built up over time. A national NGO staff member mentioned that 'The most important thing is to be accepted, and the people see us as family or they know us. In the case of South Sudan, building trust and maintaining favourable relations has two main components. The first is a cultural-community framework. Especially for actors coming from the national capital, it is considered crucial to share in the cultural, tribal and communal activities of the affected communities. The second component is less performative and is based on the presence of aid workers. Several times in interviews with aid recipients and local people from affected places, it was mentioned that the presence of a particular NGO or UN agency was considered valuable, even if they could not do much.

At the local level, then, prioritisation is largely conditional on presence and acceptance. This has major implications for the agility of aid. Needs-based humanitarianism is supposed to be capable of shifting operations when required, for example when a sudden need arises because of a disaster, but the realities on the ground paint a different picture.

\section{Interaction between the different levels}

The three levels of decision-making, to some extent, represent different realities, but there are interactions between these levels. At different moments, effective aid programming involves decisions at all three levels, and decisions at all levels largely centre on the questions of necessity, feasibility and the availability of funding. At 
each level of official and everyday politics described above, actors assess these questions within the parameters specific to that level.

The interviews also revealed flaws in the coordination and alignment between the politics of each level, even within individual organisations. Although this may be expected in any large-scale humanitarian response, the participants mentioned that the HIC in South Sudan made this more pronounced because every organisation at each level must assess their own risk, negotiate their resources, legitimate their actions and try to mesh as well as possible with the other levels.

\section{Path dependency in programming}

The decisions of how aid will be provided, when, to whom and where result from the interlocking processes of triage at the three decision-making levels. The outcomes of prioritisation reveal that humanitarian aid in South Sudan is path-dependent, meaning that decisions are largely informed by the history of interventions-not only by the analysis of current needs. This understanding is quite unlike the image of humanitarianism as needs-based, flexible and agile. Triage at all three levels is steered by (financial) feasibility. At the local level, in addition to questions of need, and this feasibility is highly intertwined with acceptance, which involves a process requiring long-term immersion and trust building in communities. As a result, most INGOs and their partner organisations decide to prioritise assisting communities where they are already working or places near these locations.

The main reasons to continue working in the same place are that security and access constraints make starting projects at new sites a difficult and lengthy enterprise; establishing rapport with local communities and recruiting and training local staff take time; and knowing the territories, people and needs provide the background needed to facilitate feasible new proposals. Although it was not explicitly mentioned in the interviews, we could also observe that an additional factor of path dependency is that (I)NGO workers feel attached or obliged to a community with which they have worked for a long time. The constraints that HIC scenarios such as South Sudan impose on organisations lead them to rely on previous programmes and field presence as a springboard for new projects. As an INGO manager summarised, 'Implementing a programme in a new place in South Sudan requires much time, funds, and logistics'. Ideally, triage aims to balance needs with feasibility; however, in reality, the feasibility aspect, which is strongly path-dependent, is assigned more weight.

The importance of path dependency for development interventions has previously been demonstrated. Koch
(Koch 2009; Koch et al. 2009) described how, at both global and national levels, INGOs tend to have certain geographical concentrations. Development thus tends to be concentrated in certain countries and in certain regions within countries. In South Sudan, we found that this pattern of path dependency is also present in humanitarian aid.

Path dependency is particularly pronounced at lower levels of decision-making. Actors and authorities operating at the national level are committed (at least in their discourses) to universal, consensual and transparent action. At this level, decisions regarding where to assist are framed on the basis of objective parameters, including the number of people affected, the level of food insecurity, the level of physical security, the health situation and water access and use. Expanding operations to lesscovered areas was discussed in multiple observed cluster meetings. Similarly, two research participants representing donors operating in the country emphasised that they encourage the institutions they fund to change or expand their operations to cover new areas. At the institutional level and especially at the local level, decisions of triage are more openly based on feasibility and often result in decisions to continue focusing on the same areas for the abovementioned reasons. Table 2 presents an example of this path dependency based on the famine declaration in South Sudan.

\section{The need for flexible programmes and adaptive management}

While HIC dynamics are an important reason why humanitarian actors are not as agile as they would like to be in responding to newly arising or changing needs, the participants in this study also emphasised the lack of flexibility built into humanitarian programming, as is clearly illustrated in the example of the famine in Table 2 . As an INGO manager explained, 'It is not that simplebeing flexible when you have a fixed budget, timelines, deadlines, budget lines, all the lines'. Many participants mentioned the lack of room for manoeuvring in the aid regime as a major impediment to flexibility.

Most INGOs represented in this study found it challenging to negotiate with donors regarding programme modification. Modifications involving changing to a different village in the same state or adjusting the specifics of the response within the same humanitarian category were considered relatively easy. For example, changing activities within the water, sanitation and hygiene sector would be possible, but shifting activities to a different category such as non-food items would not be possible. For the types of changes considered to be more difficult, INGOs and NGOs had to resort to what they referred to as 'creativity'. This 'creativity' 
Table 2 The example of path dependency in the famine response

The declaration of famine in South Sudan is a good example for studying the extent to which humanitarian action is agile and mobile or locked in a path-dependency cycle.

After famine was declared in two counties of South Sudan in February 2017, many international non-governmental organisations (INGOs) and United Nations agencies encountered a strong call (albeit contested) to prioritise the needs of people affected by the famine over the needs of those affected by the conflict and considering the difficulties of acting in a high-intensity conflict setting. There was also a call for organisations to try to change their focus of action, counteracting the trend to keep working in places where programmes have already been implemented. However, despite these organisations' drive to respond and the new resources, incentives and objectives that the famine drew to South Sudan, many INGOs were unable to respond to the 'new' crisis, access was increasingly hindered (OCHA 2017b) and the dominant strategy was to prioritise the response based on available resources (OCHA 2017a).

The main reason for this given in the interviews in this study pointed to a lack of flexibility in terms of funds and changing project and programme objectives. As one INGO manager stated, 'We cannot just re-direct funds to cover the famine response'. Similarly, aid actors mentioned that responding to the famine meant working with 'new people, new plans, new everything' and noted that it is challenging to move people and funding from one project to another. It was also mentioned that responding to the famine meant giving less priority to existing projects or altering their implementation. An INGO staff member noted that 'Emergency programmes are short term, no more than one year: any detraction and you will not be on time'. Relatedly, even with the additional funds available, acting on the famine would require modifying existing projects and reaching new agreements with donors because the organisations did not have the capacity to work on multiple complex emergencies simultaneously. In interviews with donors, they said that they would allow more time or some level of flexibility to respond to the famine; however, only a few INGOs contacted their donors to discuss this possibility.

Recent research with a panel of South Sudanese scholars and academics (see Deng 2018) also pointed out to the reduced access of information of the situation in parts of the country as an explanation for lack of actions in famine-affected areas. This panel mentioned the importance to consider the extremely low number of South Sudanese aid actor at senior management positions, which resulted in reduced access to or proper interpretation of local-level information.

A final explanation presented for the limited capacity to respond to the famine is that the declaration of famine can be seen more as a political move aiming to unleash a set of humanitarian actions than as a real famine situation. All participants were careful to clarify that this statement should not be taken to diminish the severity of the situation or the level of malnutrition experienced; however, it should be made clear that for them, a famine defined as two of every 10,000 people dying each day and over than 30\% of the population suffering acute malnutrition (FEWS 2016), is not precisely what was happening, even in the worst-affected areas of South Sudan. Therefore, although some level of response is urgently needed, the situation is not as urgent as it appears.

In summary, from a triage point of view, when deciding to respond to the famine, only a few organisations were able to organise effective responses in a short period of time and were independent enough to implement in this high-intensity conflict setting.

a A similar situation is described by Deng (2002) regarding the famine declaration of 1998 in the southern parts of Sudan, nowadays South Sudanese territory. As the author describes '[w]hen the famine occurred in 1998, some aid agencies resisted recognising the famine, preferring to "normalise" it by describing it as "extreme distress" or 'crisis' or even "normal transitory food insecurity"' (Deng 2002:36)

could entail stretching the conditions of their funding or seeking funding from different sources. The latter approach could mean raising funds from private donors to allow the organisation the flexibility needed to manoeuvre through unexpected challenges. For example, when the Government of South Sudan decided to increase the fees of the working permits for international staff, three actors (a donor and two INGO staff members) said that they dealt with this additional burden via private funding because these costs were beyond the project-planning budget.

A related impediment concerned the duration of programmes. In HIC scenarios, most funding is related to emergency and humanitarian aid actions and focuses on short or 1-year funding schemes. This works against agencies that need to change the location of their interventions: such a change will prolong existing projects because of the time needed to set up the new programme, recruit staff and foster relations with the community. Additionally, coping with short funding timeframes often entails 'creativity', whereby certain activities are postponed to the next funding cycle, which can only be done when continuing to work within the same project area.

\section{Local actors and organisations}

Creating a legitimate basis for humanitarian intervention is primarily done by working through locally embedded organisations, as was also observed by Tanner and Moro (2016) at the beginning of the conflict in South Sudan and more recently re-stated by different South Sudanese scholars (Deng 2018). These organisations are seen as legitimate by the local community and aid recipients. In this research, their legitimacy was always explained by the interviewees as part of what can be broadly called a cultural-community framework, including religion as a legitimation factor.

In South Sudan, many humanitarian workers are local, have significant family and community ties and share the same ethnic grouping or tribal group as the aid recipients. Because of the conflict, many of these actors cannot work in places that are under the control of groups that are hostile to their tribal affiliation or political association. Compared with international actors, local and regional actors are able to obtain more accurate information and are seen as legitimate actors by affected communities and local authorities. INGOs therefore usually work in partnership with local and national NGOs. Local NGO representatives mentioned 
that INGOs and UN agencies operate as mini-donors and donors, respectively, hiring local NGOs to do certain jobs. One of the reasons mentioned, besides security and access reasons, is that local NGOs provide these services cheaper compared to their international counterparts.

The reality observed on the ground in this study revealed several nuances. Local and national NGOs are the main actors involved in delivering assistance in areas directly affected by conflict or disaster and in remote areas. Coordinated regional operations and the provision of aid in protection of civilian's sites, informal camps and secure areas are often done by international actors relying mainly on South Sudanese staff members, but retaining some coordinating and managing positions for international actors from the region. International actors mentioned that the insufficiency of human resources and capacities in the country to manage major operations is related to the level of education, language barriers and lack of knowledge of operational procedures and protocol by South Sudanese workers. However, the ensuing situation gives local and national NGOs the feeling that they are being used for the 'hard and dangerous tasks' without being given the space to obtain significant grants, notwithstanding their capacities to manage such grants (see Deng 2018 too). In other words, working with local and national actors can be seen as one way of outsourcing risks. However, not every local and national actor is equally exposed to the multiple risk and consequences of working on South Sudan. Those in positions of power, with more wealth, or working with international organisations, such as INGOs or UN, might have better the means to reduce the risk of working on conflict areas. As these people operate on a distance from the affected areas, they are also less affected by the weight of understanding the everyday consequences of these decisions.

Another nuance is that often times INGOs can get 'captured' by local intermediaries or actors which want to sustain their programming in particular areas. Local actors play a role in the decision-making process by promoting or finding strategies to keep aid going to certain places or addressing it to particular areas.

Although much can be said about the division of labour between international and national actors, the most relevant implication here is that the reliance on embedded organisations further enhances the tendency of path dependence found in the organisation of aid delivery in South Sudan.

\section{Private sector support}

A final dynamic that reinforces path dependency is the use of the private sector. Most aid operations are strongly supported by the private sector, especially in terms of transportation and financial services. It was mentioned in the vast majority of the interviews and seen in observations during the field visits that private trucks and charter flights are used for the distribution of goods in South Sudan. Via the World Food Programme, the UN manages the UN Humanitarian Air Service, providing flights and transportation of goods services, but the cost or timing of these services cause many INGOs and national and local NGOs to opt for private solutions instead.

These private services are usually run by regional companies from neighbouring countries and include in their price insurance and what an interviewed truck owner called a 'full package.' This 'full package' includes the fuel, driver, delivery of the goods, some sort of insurance, information about the roads, detours, food and water for the driver and assistance with loading tasks, as well as some items that agencies cannot include in their financial reports, such as informal payments at checkpoints. Charter flights offer similar solutions, including in their prices both official airport fees and 'less-known' fees. The private sector also plays a role in providing financial services, such as the transport of money needed for cash transfer programmes, salary and service payments and the purchase of local goods. The private sector is also present in voucher and electronic card programmes, which are mainly run by UN agencies.

In general, these private services are a way of outsourcing risks and dealing legally with the irregularities and informalities found in HIC scenarios, as well as managing the insecurity and the logistics of operating in a HIC scenario such as South Sudan. The reliance on the private sector reinforces the path dependency of aid programming. Like aid agencies, private companies require deep knowledge and trusted local actors to operate; hence, these companies only offer their services in familiar territories, reinforcing the tendency for aid to be provided in the same places or near previous projects.

\section{Discussion and conclusions}

Providing humanitarian aid and disaster response in HIC scenarios is challenging for many reasons. Funding and the complex logistics necessary to overcome reduced access and insecurity emerge as the main challenges in South Sudan. However, as our study showed, aid actors are confident about their ability to operate under these daunting conditions, and there is no doubt that humanitarian assistance and disaster response can be carried out in these complex arenas of aid delivery.

This article focused on decision-making and practices around the questions of who, where and how aid will be provided. The notions of targeting and triage 
acknowledge that prioritisation is necessary and that this comes about through both assessing the needs and evaluating the capacities, feasibility and scope of the response.

There are three main research findings. First, the reality of prioritisation is very complex. It concerns three levels of decision making, each of which has specific rationales. At each level of decision-making, everyday politics plays a role and intertwines with official politics. The research thus contributes to the evolving literature on the complexity of humanitarian governance (Dijkzeul and Sandvik 2019).

Second, the research confirms that prioritisation is a painful process, first and foremost for the affected communities, but also for the aid actors involved. Whereas the concept of targeting conveys a rational process to establish needs, here, we use the concept of triage, which has historically been more associated with the painful process of deciding whom to help and whom not to help. We found that aid actors deal with this painful process by, for example, maintaining that decisions are not final (and hence aid may be reconsidered in the future) and by relying on community resilience. The latter finding tallies with the work of Jaspars (2018), who demonstrated that resilience is used as an excuse for withholding aid. We add a layer to her analysis by bringing out how aid workers use resilience to relieve the pain of decisions they are required to make. Regarding the famine in South Sudan, saying that the declaration of famine is political, although this is true (as every disaster-related action is political), is another way to alleviate the burden of deciding not to act. This result also relates to what Barnett and Snyder (2008, p. 143) have termed the 'ethics of consequentialism', as humanitarians working in HIC scenarios are constantly 'asking whether they can achieve their most preferred outcome and, if not, whether they might settle for the second- or third- ranked outcome.' Triage confronts aid actors with ethical reflections on the consequences of their actions. Our findings thus contribute to the literature on the coping mechanisms that aid workers develop to deal with the stresses of the challenging choices they have to make (Walkup 1997).

Third, we found that aid actors, especially INGOs, despite their capacity to act and their apparent flexibility, are locked into path-dependent programming. Agencies tend to stay and work in the same areas and sectors over time, rather than moving to locations where aid is needed the most. There are many factors that play into this tendency towards path dependency. These include the challenges of operating in HIC scenarios, the inflexibility of humanitarian financing, the roles of local actors and the roles of private companies involved in aid delivery. These factors all result in a tendency for agencies to continue working in the same area. The example of the famine in South Sudan further shows how each of these factors plays a role in the path-dependency cycle, even when extra funds are available, as is usually the case with famine declarations (De Waal 1997; Donini and Walker 2012; Keen 2008).

Path dependency has previously been convincingly demonstrated in development programming (Koch et al. 2009). However, to our knowledge, this is the first time humanitarian assistance, which is strongly associated with agility, has been discussed in this way. A major contribution of this article, then, is to question this agility and to suggest that humanitarian assistance is much more path-dependent than has previously been assumed. This path dependency has major consequences for the ability to respond to sudden changes in needs, for example at the moment when a disaster develops in a conflict area.

Future work is needed to understand how aid is provided in other HIC scenarios, to what extent these scenarios are similar to the case of South Sudan and how the triage of aid evolves and develops in other situations. Additional fieldwork research is also needed to better understand how humanitarian assistance and disaster response develop in practice as the layered outcome of complex decision making informed by multiple types of policy.

\section{Abbreviations \\ FSL: Food security and livelihoods; HIC: High-intensity conflict; HNO: Humani- tarian Needs Overview; HRP: Humanitarian Response Plan for South Sudan; INGO: international non-governmental organisations; NGO: Non-govern- mental organisations; OCHA : United Nations Office for the Coordination of Humanitarian Affairs; UN: United Nations.}

\section{Acknowledgements}

The authors would like to thank the numerous institutions, NGOs, INGOs and UN agencies that facilitated access and provided logistic support during the fieldwork, especially the South Sudan Joint Response (SSJR) of the Dutch Relief Alliance and its lead organisation, Save the Children Netherlands. We are also grateful to the research assistants and translators supporting the research process. Finally, we express our gratitude to the people of South Sudan for welcoming us into their country and sharing their stories and lives.

\section{Authors' contributions}

All authors read and approved the final manuscript.

\section{Funding}

This work is part of the research project 'When Disasters Meet Conflict', funded by a VICl grant from the Netherlands Organisation for Scientific Research (NWO) (Grant number: 453-14-013).

\section{Availability of data and materials \\ Not applicable.}

\section{Declarations}

Competing interests

The authors declare no competing interests.

Received: 19 June 2020 Accepted: 30 November 2021

Published online: 13 January 2022 


\section{References}

Ahrens J, Rudolph PM (2006) The importance of governance in risk reduction and disaster management. J Conting Crisis Manage 14(4):207-220. https://doi.org/10.1111/j.1468-5973.2006.00497.x

Bakewell, Oliver (2000) 'Uncovering Local Perspectives on Humanitarian Assistance and its Outcomes', Disasters 24(2):103-16

Barnett MN, Weiss TG (eds) (2008) Humanitarianism in question: politics, power, ethics. Cornell University Press, Ithaca

Barnett M, Snyder J (2008) The grand strategies of humanitarism. In: Barnett M, Weiss TG (eds) Humanitarianism in Question: Politics, Power, Ethics. Cornell University Press, Ithaca, pp 143-172

Benson C, Twigg J, Rossetto T (2007) Tools for mainstreaming disaster risk reduction: guidance notes for development organisations. Provenium Consortium and the International Federation of Red Cross and Red Crescent Societies), Geneva

Buckle P (2012) Preparedness, warning and evacuation. In: Wisner B, Gaillard J, Kelman I (eds) The Routledge handbook of hazards and disaster risk reduction. Routledge, London, pp 493-504

Caso N (2019) Human development, climate change, disasters and conflict: linkages and empirical evidence from the last three decades. Thesis, International Institute of Social Studies of Erasmus University Rotterdam, The Hague

Cole D (2017) South Sudan will now charge $\$ 10,000$ for an aid worker permit. Why? NPR Retrieved June 19, 2017 (http:// www.npr.org/sections/goatsandsoda/2017/03/07/519048728/ south-sudan-will-now-charge-10-000-for-an-aid-worker-permit-why)

Davoudi S (2012) Resilience: a bridging concept or a dead end? Plan Theory Pract 13(2):299-333

De Waal A (1997) Famine crimes: politics \& the disaster relief industry in Africa. African Rights \& the International African Institute in association with James Currey, Oxford \& Indiana University Press, Bloomington, London

Deng D (2018) The politics of humanitarianism: perspectives from South Sudan. London School of Economics, UK

Deng LB (2002) The Sudan famine of 1998. IDS Bull 33(4):28-38. https://doi. org/10.1111/j.1759-5436.2002.tb00041.x

Dijkzeul D, Sandvik KB (2019) A world in turmoil: governing risk, establishing order in humanitarian crises. Disasters 43(S2):S85-S108. https://doi.org/ 10.1111/disa.12330

Donini A, Walker P (2012) So What? In: Donini A (ed) The golden fleece: manipulation and independence in humanitarian action. Kumarian Press, Sterling, pp 243-263

Duffield M (1994) Complex emergencies and the crisis of developmentalism. IDS Bull 25(4):37-45

FEWS. 2016. Guidelines for IPC Famine Classification. Famine Early Warning Systems Network.

Field J, Kelman I (2018) The impact on disaster governance of the intersection of environmental hazards, border conflict and disaster responses in Ladakh, India. Int J Disast Risk Reduct 31:650-658. https://doi.org/10. 1016/j.ijdrr.2018.07.001

Gaffey, Conor. 2017. "As South Sudan battles famine, aid workers remain under fire." Newsweek. Retrieved May 12, 2017 (http://www.newsweek.com/ south-sudan-famine-aid-workers-589653).

George AL, Bennett A (2005) Case studies and theory development in the social sciences. MIT Press, Cambridge

Gerring J (2007) Case study research: principles and practices. Cambridge University Press, New York

Ginige K, Amaratunga D, Haigh R (2010) Developing capacities for disaster risk reduction in the built environment: capacity analysis in Sri Lanka. Int J Strat Property Manag; Vilnius 14(4):287-303

Government of the Republic of South Sudan (2015) Official statement of the Republic of South Sudan at United Nations Third World Conference on Disaster Risk Reduction. In: Presented at the Third UN World Conference on Disaster Risk Reduction (WCDRR), May, Sendai, Japan

Healy S, Tiller S (2014) Where is everyone? Responding to Emergencies in the Most Difficult Places. Médecins Sans Frontières, London

Hilhorst D (2013) Disaster, conflict and society in crises: everyday politics of crisis response. In: Hilhorst D (ed) Disaster, conflict and society in crises: everyday politics of crisis response, Routledge humanitarian studies series. Routledge, New York, pp 1-15

Hilhorst D (2018) Arenas. In: Allen T, Macdonald A, Radice H (eds) Humanitarianism: a dictionary of concepts. Routledge, London, pp 30-51
Hilhorst D, Desportes I, de Milliano CWJ (2019a) Humanitarian governance and resilience building: Ethiopia in comparative perspective. Disasters 43(S2):S109-S131. https://doi.org/10.1111/disa.12332

Hilhorst D, Jansen B (2010) Humanitarian space as arena: a perspective on the everyday politics of aid. Dev Change 41(6):1117-1139

Hilhorst D, Jansen B (2013) Humanitarian space as arena: a perspective on the everyday politics of aid. In: Disaster, conflict and society in crises: everyday politics of crisis response, Routledge humanitarian studies series. Routledge, New York, pp 187-204

Hilhorst D, Mena R, van Voorst R, Desportes I, Melis S (2019b) Disaster risk governance and humanitarian aid in different conflict scenarios. In Global Assessment Report on Disaster Risk Reduction (GAR 2019) (p. 49). United Nations Office for Disaster Risk Reduction (UNDRR). Geneva. https://www. preventionweb.net/publications/view/65903

Hopgood S (2008) Saying 'no' to Wal-Mart? Money and Morality in Professional Humanitarism. In: Humanitarianism in Question: Politics, Power, Ethics. Cornell University Press, Ithaca, pp 98-142

IASC (2015) Humanitarian response quidance 2016. Inter-Agency Standing Committee; OCHA. Geneva. https://www.humanitarianresponse.info/ en/programme-cycle/space/document/humanitarian-response-monit oring-guidance

Jaspars S (2018) Food aid in Sudan: a history of power, politics and profit. Zed Books Ltd, London

Keen D (2008) The benefits of famine: a political economy of famine and relief in Southwestern Sudan, 1983-1989. 1st paperback ed. James Currey Publishers; Ohio University Press; Fountain Publisher, Oxford: Athens : Kampala

Kelman I (2008) Relocalising disaster risk reduction for urban resilience. Proc Instit Civil Eng - Urban Design Plann 161(4):197-204. https://doi.org/10. 1680/udap.2008.161.4.197

Kerkvliet B (2009) Everyday politics in peasant societies (and Ours). J Peasant Stud 36(1):227-243. https://doi.org/10.1080/03066150902820487

Koch D-J (2009) Blind spots on the map of aid allocations concentration and complementarity of international NGO aid. Routledge, New York

Koch D-J, Dreher A, Nunnenkamp P, Thiele R (2009) Keeping a low profile: what determines the allocation of aid by non-governmental organizations? World Dev 37(5):902-918

Little S (2017) South Sudan: time for humanitarians to get tough. IRIN. London. Retrieved August 7, 2017. (https://www.thenewhumanitarian.org/opini on/2017/08/07/south-sudan-time-humanitarians-get-tough)

Manyena B, O'Brien G, O'Keefe P, Rose J (2011) Disaster resilience: a bounce back or bounce forward ability? Local Environ 16(5):417-424. https://doi. org/10.1080/13549839.2011.583049

Marriage Z (2006) The comfort of denial: external assistance in Southern Sudan. Dev Change 37(3):479-500. https://doi.org/10.1111/j.0012-155X. 2006.00487.x

Maxwell DG, Majid N (2015) Famine in Somalia: competing imperatives collective failures, 2011-12. Hurst \& Company, London

Maxwell D, Watkins B (2003) Humanitarian information systems and emergencies in the Greater Horn of Africa: logical components and logical linkages. Disasters 27(1):72-90. https://doi.org/10.1111/1467-7717.00220

Maxwell D, Young H, Jaspars S, Frize J, Burns J (2011) Targeting and Distribution in Complex Emergencies: Participatory Management of Humanitarian Food Assistance. Food Policy 36(4):535-543. https://doi.org/10.1016/j. foodpol.2011.03.010

Mena R (2018) Responding to socio-environmental disasters in high-intensity conflict scenarios: challenges and legitimation strategies. In: Brauch HG, Spring ÚO, Collins AE, Oswald SES (eds) Climate Change, Disasters, Sustainability Transition and Peace in the Anthropocene, Politik - Economics - Society - Science (APESS). Springer, Berlin, pp 27-66

OCHA (2016) 2017 Humanitarian Response Plan: South Sudan. OCHA, United Nations

OCHA (2017a) South Sudan 2018 Humanitarian response plan. UN Office for the Coordination of Humanitarian Affairs (OCHA), Juba

OCHA (2017b) South Sudan: humanitarian access snapshot (June 2017). UN Office for the Coordination of Humanitarian Affairs (OCHA, Juba

OCHA (2018) On-Site Operations Coordination Centre (OSOCC) Guidelines 2018. United Nations Office for the Coordination of Humanitarian Affairs (OCHA)

Orbinski J (2009) An imperfect offering: dispatches from the medical frontline. Rider, London 
Orbinski J, Reed P (2009) Film synopsis: 'Triage: Dr. James Orbinski's Humanitarian Dilemma. Dr. James Orbinski's Humanitarian Dilemma, Triage Retrieved March 22, 2017 (http://www.whitepinepictures.com/triage/)

Patel RB, King J, Phelps L, Sanderson D (2017) What practices are used to identify and prioritize vulnerable populations affected by urban humanitarian emergencies? Feinstein International Center; UKAID, Oxfam

Paton D, Smith L, Violanti J (2000) Disaster response: risk, vulnerability and resilience. Disast Prev Managt: Int J 9(3):173-180. https://doi.org/10.1108/ 09653560010335068

Peters K (2017) The next frontier for disaster risk reduction. ODI (Overseas Development Institute), London

Redfield P (2008) Sacrifice, triage and global humanitarianism. In: Humanitarianism in Question: Politics, Power, Ethics, edited by M. Barnett and T. G. Weiss. Cornell University Press, Ithaca, pp 196-214

Rose J, Jayawickrama J (2016) Capacity building of institutions for disaster risk reduction: learning from communities as first responders. Built Environ Project Asset Manag 6(4):391-402. https://doi.org/10.1108/ BEPAM-06-2015-0024

Tanner L, Moro L (2016) Missed Out: The role of local actors in the humanitarian response in the South Sudan conflict. Oxfam GB, CAFOD and Trócaire in partnership, Christian Aid, Tearfund. South Sudan. https://doi.org/10. 21201/2016.606290

Tierney K (2012) Disaster governance: social, political, and economic dimensions. Annu Rev Env Resour 37(1):341-363. https://doi.org/10.1146/annur ev-environ-020911-095618

UNDP (2010) Capacity Development for Disaster Risk Reduction. United Nations Development Programme (UNDP), New York

UNHCR (2017) South Sudan Situation. United Nations High Commissioner for Refugees (UNHCR) https://www.unhcr.org/593e9e9b7.pdf

UNISDR (2017) Terminology. UNISDR Retrieved (https://www.unisdr.org/we/ inform/terminology)

United Nations (2017) Famine declared in region of South Sudan - UN. UN News Retrieved (https://news.un.org/en/story/2017/02/551812-faminedeclared-region-south-sudan-un)

USAID, FEWS (2011) IPC acute food insecurity reference table for household groups. FEWS Net; USAID Retrieved June 2, 2020 (http://www.fews.net/ $\mathrm{ml} / \mathrm{en} / \mathrm{info} /$ pages/scale.aspx)

van Voorst R, Hilhorst D (2017) Humanitarian action in disaster and conflict settings. International Institute of Social Studies, EUR, The Hague

Walkup M (1997) Policy dysfunction in humanitarian organizations: the role of coping strategies, Institutions, and Organizational Culture. J Refugee Stud 10(1):37-60

WFP (2006) Targeting in Emergencies, 5th edn. World Food Programme, Rome WHO (2017) WHO South Sudan Crisis. World Health Program, United Nations Retrieved May 22, 2017 (http://www.who.int/emergencies/south-sudan/ en/)

Wisner B (2012) Violent Conflict, Natural Hazards and Disaster. In: Wisner B, Gaillard J, Kelman I (eds) The Routledge handbook of hazards and disaster risk reduction. Routledge, London, pp 65-76

Wisner B, Gaillard JC, Kelman I (2012) Framing disaster: theories and stories seeking to understand hazards, vulnerability and risk. In: Wisner B, Gaillard J, Kelman I (eds) The Routledge handbook of hazards and disaster risk reduction. Routledge, London, pp 18-33

Wood AP, Apthorpe RJ, Borton J (eds) (2001) Evaluating International Humanitarian Action: Reflection from Practitioners. Zed Books, London

Young H, Maxwell D (2009) Targeting in complex emergencies: Darfur case study. In: Feinstein International Center Report (Part of Larger Study Commissioned by WFP). Tufts University 1, Medford

\section{Publisher's Note}

Springer Nature remains neutral with regard to jurisdictional claims in published maps and institutional affiliations.

\section{Submit your manuscript to a SpringerOpen ${ }^{\odot}$ journal and benefit from:}

- Convenient online submission

- Rigorous peer review

- Open access: articles freely available online

- High visibility within the field

- Retaining the copyright to your article

Submit your next manuscript at $\boldsymbol{\nabla}$ springeropen.com 